\title{
POLÍTICAS DE INFORMAÇÃO NAS BIBLIOTECAS UNIVERSITÁRIAS: UM ENFOQUE NO DESENVOLVIMENTO DE COLEÇÕES
}

\author{
INFORMATION POLICY IN THE UNIVERSITY LIBRARIES: \\ AN APPROACH IN THE COLLECTION DEVELOPMENT
}

\author{
Geneviane Duarte Dias ${ }^{1}$ \\ Terezinha Elizabeth da Silva ${ }^{2}$ \\ Brígida Maria Nogueira Cervantes ${ }^{3}$
}

Resumo:Apresenta um recorte histórico sobre a importância da política de informação científica e tecnológica no cenário universitário, especialmente nas bibliotecas universitárias, apresentando quais os mecanismos e influências que determinaram a sua socialização durante as décadas de 1950 - 1980 . Oferece uma reflexão sobre o desenvolvimento de coleções, sua importância e a necessidade de implementação nos acervos das bibliotecas universitárias, servindo de base para o planejamento das normas e diretrizes, facilitando, assim, o crescimento racional e equilibrado do acervo.

Palavras-chave: Política de informação. Desenvolvimento de coleções. Bibliotecas universitárias.

Abstract: Shows a historical view on the importance of the policy of scientific and technological information in the university setting, especially in university libraries, with which the mechanisms and influences which determine their socialization during the decades from 1950 to 1980. It offers a reflection on the development of collections, its importance and necessity of implementing the collection of university libraries, serving as a basis for planning policies and guidelines, aiding the rational and balanced growth of the acquis.

Keywords: Information policy. Collections development. University libraries.

\footnotetext{
${ }^{1}$ Mestranda do Programa de Pós-Graduação em Gestão da Informação, Universidade Estadual de Londrina. Bibliotecária, Universidade Estadual de Londrina (UEL). Londrina, PR, Brasil. E-mail: genevianeduarte@gmail.com

${ }^{2}$ Docente Sênior do Programa de Pós-Graduação em Gestão da Informação (MP), Centro de Educação, Comunicação e Artes, Universidade Estadual de Londrina. Londrina, PR, Brasil. E-mail: terezinhaelizabeth@gmail.com

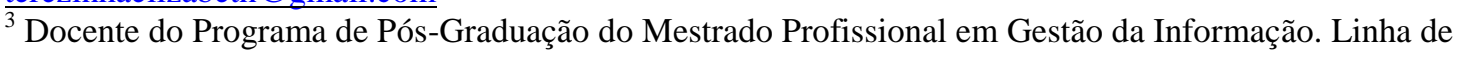
Pesquisa: Organização e Representação da Informação e do Conhecimento. Universidade Estadual de Londrina. Londrina, PR, Brasil. E-mail: brigidacervantes@gmail.com

Enviado em: 24/04/2012 - Aceito em: 05/12/2012.
}

\begin{tabular}{l|l|l|l|l|l|l|} 
(C) Rev. digit. bibliotecon. cienc. inf. & Campinas, SP & v.11 & n.1 & p.39-54 & jan./abr. 2013 & ISSN 1678-765X \\
\hline
\end{tabular}




\section{INTRODUÇÃO}

Em decorrência da institucionalização de programas e ações implementados por institutos e organismos governamentais, bem como da implantação da Reforma Universitária em 1968, culminou uma nova estrutura acadêmica, acelerando o processo de desenvolvimento científico nas universidades brasileiras. Concomitantemente, a temática que envolve o desenvolvimento de coleções tem sido alvo de muitas discussões e trabalhos de muitos estudiosos. Podemos identificar essas discussões nos trabalhos de Vergueiro (1989; 1993); Weitzel (2006); Miranda (2007), entre outros.

Nessa perspectiva, este estudo tem por objetivo apresentar conceitos históricos básicos, porém relevantes, concernentes à Política de Informação Científica e Tecnológica (ICT) no contexto das bibliotecas universitárias, com seu enfoque voltado à importância do desenvolvimento de coleções, considerando suas características peculiares.

\section{POLÍTICA DA INFORMAÇÃO NO CONTEXTO DAS BIBLIOTECAS UNIVERSITÁRIAS}

A década de 1950 marca o início da institucionalização de vários organismos, programas, centros científicos e informacionais, institutos de pesquisa, bem como o desenvolvimento das políticas públicas de Ciência e Tecnologia (C\&T). Os primeiros encaminhamentos do governo para a organização e planejamento das atividades de ciência e tecnologia centralizam esforços na formação do Conselho Nacional de Pesquisa (CNPq), da Campanha Nacional de Aperfeiçoamento de Pessoal de Nível Superior (CAPES) e do Instituto Brasileiro de Bibliografia e Documentação (IBBD) (AMARAL, 1991; SILVA, 2009).

A lei $\mathrm{n}^{\circ} .1 .310$, que criou o CNPq, datada de 15 de janeiro de 1951, estabelecia como suas finalidades promover e estimular o desenvolvimento da investigação científica e tecnológica, mediante a concessão de recursos para pesquisa, formação de pesquisadores e técnicos, cooperação com as universidades brasileiras e intercâmbio com instituições estrangeiras, executando pesquisas relevantes e necessárias importantes para o progresso sócio-econômico do país (CNPQ, 2011).

Transcorridos alguns meses de criação do CNPq, especificamente em 11 de julho de 1951, foi criada a CAPES, a tão aspirada agência de fomentos, cujo objetivo principal era \begin{tabular}{l|l|l|l|l|l|l}
\hline (C) Rev. digit. bibliotecon. cienc. inf. & Campinas, SP & v.11 & n.1 & p.39-54 & jan./abr. 2013 & ISSN 1678-765X \\
\hline
\end{tabular} 
assegurar a existência de pessoal especializado em quantidade e qualidade suficientes para atender às necessidades dos empreendimentos públicos e privados que visavam ao desenvolvimento do Brasil (CAPES, 2011). A criação do IBBD aconteceu em 27 de fevereiro de 1954. O objetivo principal do IBBD era servir como centro de informações científicas para os pesquisadores e estudiosos do país, onde desde algum tempo, cogitava-se a organização de um centro nacional de bibliografia (BRASIL, 2005; BRASIL, 2011; CNPq..., 2001; SILVA, 2009).

Por sua vez, na década de 1960, o país enfrentava uma nova fase político-econômica com o golpe militar em 1964. A ênfase na política nacional sofria alterações relevantes e priorizava seu enfoque na segurança, na economia e no desenvolvimento. O CNPq sofreu reformulações, ficando com a missão de elaborar uma política para o setor científico, sob a forma do Plano Quinquenal de Desenvolvimento Científico. Nesse cenário, foi formulado o Programa Estratégico de Desenvolvimento (PED), que propunha uma política científica e tecnológica de forma explícita e sistematizada, culminando na criação do Fundo Nacional de Desenvolvimento Científico e Tecnológico (FNDCT), com o objetivo principal de financiamento à pesquisa no país (AMARAL, 1991; SILVA, 2009).

O período 1970 a 1980 foi marcado pelo estabelecimento de programas e projetos de desenvolvimento científico e tecnológico, seguido pelo acréscimo de recursos financeiros e organismos burocráticos destinados especialmente a dar apoio financeiro a esses setores. Os países mais avançados, respaldados na ideia de que a ICT assumia importância no desenvolvimento e na hegemonia científico-tecnológico internacional, implementaram efetivamente suas políticas na área. Concomitantemente, no Brasil, o Estado atribuiu importante relevância ao papel da ICT e implementou projetos integrados de industrialização, de pesquisa e de ensino baseados numa política científica e tecnológica (AMARAL, 1991; COSTA, 1991; GOMES, 1988; SILVA, 2009).

Ainda na década de 1970, ocorre uma mudança da nomenclatura do IBBD. O CNPq criou, por meio da Resolução n. ${ }^{\circ}$ 20/76 de 25 de março de 1976, o Instituto Brasileiro de Informação em Ciência e Tecnologia (IBICT), o qual tentou dar continuidade às ações de seu antecessor e refletir as transformações ocorridas na área, reafirmando a relevância do papel das tecnologias em seu desenvolvimento. O maior fator de transformação do IBBD em IBICT foi o desejo de transformar essa nova agência em um órgão central que pudesse desempenhar, 
de forma descentralizada, as funções de coordenação das atividades de ICT (CUNHA, 2005; CORREA, 2008).

No Brasil, a ICT carece de mais estudos que possibilitem uma luz sobre as questões de disponibilidade e acesso à informação nas bibliotecas e no ciberespaço. Ademais, pode-se perceber que, durante três décadas, as preocupações com a ICT apareceram embutidas nas ações definidas nos programas ou nas políticas científicas e tecnológicas estabelecidas pelos órgãos e pelas instituições competentes que passaram a promover a importância da C\&T (SILVA, 2009).

Sendo assim, é especialmente importante apresentar alguns conceitos sobre política de informação, visando a uma melhor compreensão dessa temática. Na visão de Silva (1991, p. 11), uma "Política de informação significa uma decisão governamental, direcionando as atividades do setor. Explícita ou implícita - difusa na massa das políticas públicas - ela é o resultado de uma correlação de forças dentro do Estado." Segundo Aun (1999, p. 3), “A construção de uma política de informação implica o que é verdadeiramente prioritário: a articulação de medidas para que a sociedade se desenvolva de forma justa e democrática." Na concepção de Caridad Sebastián, Méndez Rodriguez e Rodriguez Mateos (2000), uma política de informação é um planejamento de um projeto em que a declaração da missão é essencial para se estabelecer as linhas de ação que se deseja seguir.

Outra definição que auxilia na compreensão é a de González de Gómez (2002), o qual salienta que a política de informação pode ser entendida como o conjunto de ações e decisões orientadas a preservar e a reproduzir ou a mudar e substituir um regime de informação, podendo ser tanto políticas tácitas ou explícitas, micro ou macro ${ }^{4}$. Segundo Orna (2008), os governos começaram a se preocupar com a ideia de "informação política" em torno do final dos anos 1970 e início dos anos 1980. A autora chama a atenção para um elemento importante da história que deve ser mencionado: a vertente que se preocupava com a informação científica e tecnológica, o que contribuiu tanto para o conceito de política de informação, como para o desenvolvimento da própria Ciência da Informação (tradução nossa).

\footnotetext{
${ }^{4}$ Políticas tácitas são aquelas não expressas, mas que se encontram subsumidas em outras normas, ao passo que as políticas explícitas são claramente definidas em documentos. Em termos de abrangência, as políticas micro destinam-se a setores, regiões restritas e organizações, enquanto que as políticas macro são aquelas que dizem respeito a questões de maior abrangência e são, de maneira geral, pensadas em nível de Estado.
}

\begin{tabular}{l|l|l|l|l|l|l|} 
(C) Rev. digit. bibliotecon. cienc. inf. & Campinas, SP & v.11 & n.1 & p.39-54 & jan./abr. 2013 & ISSN 1678-765X \\
\hline
\end{tabular}


Nesse cenário de políticas e programas referentes à ICT, destacam-se as bibliotecas universitárias, que reivindicavam recursos e soluções para problemas estruturais, tais como ensino público deficiente e infraestrutura de C\&T, desde 1968, quando da reforma universitária (BARBOSA, 2004). Essa concepção de biblioteca ligada às ordens religiosas, que deram sustentação ao movimento de criação das universidades, surgiu na Idade Média. Embora, naquela época, os livros fossem manuscritos, o que dificultava e encarecia sua reprodução, as universidades sempre dispuseram de bibliotecas, mesmo que de forma elementar e incipiente (CARVALHO, 2004; VERGER, 1999).

A Universidade de Paris foi a primeira instituição que impulsionou este "[...] modelo de biblioteca laica e especializada através da Biblioteca de Sorbonne, nome dado em homenagem ao religioso Robert de Sorbon, doador dos primeiros exemplares integrantes da biblioteca." (NUNES; SANTOS, 2007, p. 3). Segundo os autores, apesar dessas bibliotecas surgirem vinculadas a ordens eclesiásticas, as universidades difundiram e disseminaram acentuadamente o modelo de biblioteca que evoluiria até os moldes atuais. Tarapanoff (1981, p. 10) argumenta que:

\begin{abstract}
A biblioteca universitária é uma organização sem autonomia própria, sendo dependente da universidade à qual pertence. $\mathrm{O}$ seu relacionamento com a sociedade se faz através da universidade e não diretamente. O relacionamento da universidade com a sociedade é seletivo, sujeito às funções da universidade dentro desta sociedade e de suas decisões e 'negociações' políticas. Este relacionamento é mutável no tempo e no espaço. A universidade e a biblioteca universitária brasileiras são produtos da história social, econômica e cultural do país, bem como das características regionais brasileiras.
\end{abstract}

O marco das mudanças ocorridas nas bibliotecas universitárias sucedeu durante a Reforma Universitária de 1968 que reordenou o sistema de ensino superior, transformando faculdades e escolas em universidades e remodelando a forma de gerenciar. Essa transformação atingiu especialmente as bibliotecas (SILVA, 2009). Nessa direção, a organização das bibliotecas universitárias, na visão de Silva (1981, p. 54), acompanhou o modelo de “[...] organização das diversas universidades do País que foram formadas a partir da reunião de Faculdades e Escolas de ensino superior autônomas, estaduais e federais [...]" existentes naquela época. Em decorrência desse fluxo de mudanças, ocorreram implicações relativas à adoção de tal modelo, dessa maneira “[...] os problemas internos das bibliotecas das faculdades tornaram-se problemas dos sistemas de bibliotecas das universidades, intensificando a dimensão e 
complexidade dos serviços e da administração destas unidades de informações." (SILVA; GARCIA, 2009, p. 14).

Na década de 1970, devido às preocupações referentes às questões e discussões que envolviam o contexto das bibliotecas universitárias, um grupo de bibliotecários se organizou e criou um evento para tratar desses assuntos, denominado Seminário Nacional de Bibliotecas Universitárias (SNBU). Silva (2009, p. 32) salienta que as discussões das temáticas que se desencadearam no contexto histórico das bibliotecas universitárias podem ser sintetizadas "“[...] em torno da acirrada discussão entre a centralização ou não da administração das bibliotecas, questões referentes à arquitetura de bibliotecas, automação do acervo, compra de equipamentos e aquisição de periódicos e livros." Contemporaneamente, pode-se adicionar a essa relação discussões nos campos de Gestão de Bibliotecas Universitárias e Tecnologia da Comunicação e Informação. É possível identificar esses pensamentos nos trabalhos de Aguiar Plobación e colaboradores (2002); Dutra e Ohira (2004); Noronha e colaboradores (2006), entre outros.

Ainda durante a década de 1970, em decorrência das questões suscitadas, bibliotecários e dirigentes de bibliotecas se articularam e reuniam-se com o objetivo de trocar informações e propor soluções para os problemas existentes, tais soluções constituíam-se em automação de acervo, desenvolvimento de coleções, qualificação de bibliotecários e outros profissionais e ausência de diretrizes de planejamento e avaliação de serviços (SILVA, 2009). Nesse panorama, as bibliotecas reivindicavam uma política ou órgão que as representassem junto ao governo, porém, diferente do IBICT, que tratava da informação científica e tecnológica de uma forma geral e não exclusivamente das bibliotecas universitárias (SILVA, 2009).

Por meio da intensa atuação de planejamento iniciada na década de 1970, bem como da integração dos atores envolvidos com a problemática das bibliotecas universitárias (reitores, órgãos de fomento, dirigentes de órgãos governamentais e representantes das bibliotecas), a concepção de um plano voltado para as bibliotecas foi aceito, tornando-se especificamente o Plano Nacional para Bibliotecas Universitárias (PNBU). Na concepção de Silva (2009, p. 96-97), "Essa integração fortaleceu o plano proporcionando a viabilidade das ações e representando um poder na esfera da negociação governamental.”

Durante séculos as bibliotecas têm sido os repositórios da informação e do conhecimento das universidades e seu surgimento deu-se em decorrência da necessidade de especialização dos acervos, visando a atender ao público acadêmico de forma específica e

\begin{tabular}{l|l|l|l|l|l|l}
\hline (c) Rev. digit. bibliotecon. cienc. inf. & Campinas, SP & v.11 & n.1 & p.39-54 & jan./abr. 2013 & ISSN 1678-765X \\
\hline
\end{tabular}


direcionada a cada área do conhecimento (NUNES; SANTOS, 2007). Nesse viés, Tarapanoff (1981) complementa que as bibliotecas universitárias, a força motriz das universidades, possuem a missão de prover a infraestrutura bibliográfica, documentária e informacional para apoiar as atividades da universidade, centrando seus objetivos nas necessidades de informação do indivíduo, membro da comunidade universitária. Segundo a autora, "[...] podemos dizer que a biblioteca universitária brasileira reflete as características e é resultado da situação sócio-econômica da universidade brasileira.” (TARAPANOFF, 1981, p. 16).

Evidentemente, no campo da ciência e tecnologia, as bibliotecas universitárias ocupam um papel de destaque, abrigando as mais ricas coleções bibliográficas e de multimídia, destinadas ao campo da C\&T, tornando-se um portal do conhecimento para o mundo da comunicação e informação. Para manutenção do acervo, de equipamentos e serviços, são destinados recursos do Ministério de Educação e Cultura (MEC) e da CAPES (BARBOSA, 2004).

Por outro lado, Costa (1991, p. 33) analisa que, infelizmente, a educação nas universidades brasileiras, devido a problemas de contingente do sistema que o comporta e à ausência de uma política setorial mais intensa, “[...] não consegue integrar à maioria da comunidade acadêmica no processo de investigação, produção e absorção crítica do conhecimento." Para o autor, a universidade tem contribuído muito pouco nas questões informacionais e intelectuais que atingem diretamente a sociedade brasileira. Corroborando o pensamento de Costa, Silva (2009) destaca que, embora as bibliotecas universitárias sejam subordinadas ao MEC, que integra o sistema de C\&T, muitas vezes, elas não figuram nos planos, programas e orçamentos de C\&T e também não têm uma política específica para elas.

\footnotetext{
A descontinuidade de programas, ações e projetos e a prática de criação e de extinção de instituições consubstanciam os avanços e os retrocessos na história da ICT e das bibliotecas brasileiras. A relação de representação administrativa e política navegam ao sabor dos humores dos administradores. (SILVA, 2009, p. 17).
}

Diante do exposto, Silva (2009, p. 107-108) afirma a necessidade da construção de ações de caráter político para que as bibliotecas universitárias sejam beneficiárias e proponentes efetivas de uma política pública de ICT e, neste sentido, sugere as seguintes ações: 
a) Inclusão das bibliotecas por meio de algum órgão ou agência ministerial nas instâncias governamentais;

b) Definição de uma agenda de ações de desenvolvimento para as bibliotecas com definição de recursos financeiros e materiais, de objetivos e metas, bem como dos indicadores de avaliação e desempenho;

c) A inclusão das bibliotecas nos orçamentos das universidades, proporcionando autonomia aos gestores dessas unidades informacionais;

d) Capacitação de bibliotecários, envolvendo noções modernas de gestão, política, elaboração de projetos passíveis de candidatarem-se a editais, avaliação e desenvolvimento de indicadores de desempenho.

$\mathrm{Na}$ concepção do autor, essa capacitação poderá auxiliar na negociação entre bibliotecários e gestores das universidades, fornecendo ao gestor bibliotecário informações e subsídios concretos para tomada de decisão adequada e uma argumentação "[...] mais segura para pleitear recursos humanos, materiais e financeiros e adquirir uma posição condizente com suas responsabilidades e sua participação dentro do processo de ensino, pesquisa e extensão da universidade." (SILVA, 2009, p. 108).

É finalidade das políticas de informação coordenar ações que visam integrar as bibliotecas à realidade educacional e administrativa da universidade, implementando políticas de planejamento, fomento à pesquisa, gerenciamento das tecnologias e desenvolvimento de coleções e serviços de informação. Uma das funções que mais necessita de atenção no gerenciamento de uma biblioteca universitária é o desenvolvimento de coleções. O objetivo desse processo é incorporar as bibliotecas à política educacional e administrativa da universidade, bem como, dar apoio aos programas de ensino, pesquisa e extensão, incentivando a produção técnico-científica e artística dessas instituições. Deste processo depende a formação, o desenvolvimento racional e equilibrado do material de informação que irá subsidiar efetivamente as necessidades informacionais da comunidade universitária. Devese considerar também que esta temática tem sido destacada na literatura como uma das mais importantes atividades intelectuais do bibliotecário, muito embora a mesma literatura reporte a dificuldade de tornar a teoria uma prática sistemática (BARBOSA, 2004). 


\section{O DESENVOLVIMENTO DE COLEÇÕES NAS BIBLIOTECAS UNIVERSITÁRIAS}

A temática desenvolvimento de coleções nunca foi uma tarefa fácil, principalmente em função da sua natureza técnica e de vários fatores que militam contra esta atividade. Desenvolver coleções refere-se ao processo de, sistematicamente, construir coleções de bibliotecas para servir de estudo, ensino, pesquisa e outras necessidades pertinentes aos usuários de uma biblioteca, tornando-se o mediador entre os materiais de informação e a comunidade universitária. Nesse sentido, Klaes (1991, p. 31) acentua que "O desenvolvimento de coleções constitui uma das atividades mais importantes, na medida em que dela depende a provisão dos recursos informacionais da biblioteca [...]”. A denominação acervo/coleção bibliográfica compreende a reunião parcial ou total dos documentos disponibilizados à comunidade, independentemente do suporte ou formato em que a informação pode se apresentar (impresso, eletrônico ou digital). É essencial atribuir a importante relevância do desenvolvimento de coleção no processo de planejamento e tomada de decisão em uma biblioteca. Na concepção de Vergueiro (1993), o desenvolvimento de coleções deve constituir uma "divisão funcional da biblioteca", assim como as demais divisões (catalogação, referência, aquisição e circulação).

Cada biblioteca possui uma comunidade de usuários com necessidades de informações diferenciadas e a reunião e interpretação dessas necessidades é definitivamente uma tarefa árdua, firmando um grande desafio aos gerenciadores de coleção em uma biblioteca (ADEKANMBI; BOADI, 2008, tradução nossa). Complementando tais ideias, Weitzel (2002, p. 3) considera que:

Refletindo essa limitação humana, o desenvolvimento de coleções tornou-se recurso fundamental para se administrarem às coleções de acordo com os interesses e o perfil daqueles que necessitam de informações específicas. Esse processo funciona como filtro do conhecimento registrado, separando o joio do trigo para consumo adequado.

O processo de desenvolvimento de coleção inclui a seleção de materiais atuais e retrospectivos, o planejamento de estratégias para continuar a aquisição e a avaliação de coleções para determinar se elas correspondem às necessidades da comunidade usuária. Paralelamente, para alcançar esses objetivos, um dos propósitos fundamentais da biblioteca universitária é " [...] suprir as demandas e necessidades informacionais de sua comunidade discente, docente e de 
pesquisadores, refletidas em conteúdos programáticos ou em projetos acadêmicos dos cursos oferecidos pela Unidade que a abriga." (MACHADO; SILVA, 2002, p. 2).

Nesse contexto, as bibliotecas universitárias possuem uma função importante na evolução e desenvolvimento dessa temática, cumprindo um "[...] papel de excelência na formação acadêmica para a competência no uso de informação, pois, notadamente, o universo do conhecimento e dos processos de pesquisa passa, necessariamente, pelo mundo da documentação." (CAVALCANTE, 2006, p. 56). As bibliotecas universitárias visam satisfazer as necessidades informacionais de seus usuários e, neste sentido, têm como objetivo formar e desenvolver coleções, bem como promover o acesso ao conhecimento e à informação, auxiliando no cumprimento das finalidades da Universidade: ensino, pesquisa e extensão.

A preocupação com a política de desenvolvimento de coleções na biblioteca universitária brasileira surge entre o final da década de 1970 e início de 1980. Naquela época, não havia literatura em português sobre o assunto e o ensino da disciplina de Formação e Desenvolvimento de Coleções tinha sido recém-introduzido nas escolas de Biblioteconomia. Ainda que o contexto atual se apresente mais favorável, com o passar do tempo, as bibliotecas universitárias brasileiras quase não modificaram suas atividades de desenvolvimento de coleções (WEITZEL, 2006). As coleções que eram formadas de maneira elementar exigem, na atualidade, uma gestão criteriosa e atenta em seu processo de desenvolvimento, de modo que seja possível determinar diretrizes para nortear sua implementação (WILLIAMS; FLETCHER, 2006, tradução nossa).

O desenvolvimento de coleções é um trabalho de planejamento, interrupto e cíclico, que serve a uma determinada comunidade, envolvendo as atividades de seleção, aquisição, desbastamento e avaliação (VERGUEIRO, 1989; WEITZEL, 2006). Na concepção de Miranda (2007), uma das etapas mais importantes da política de desenvolvimento de coleções é o processo de seleção, “[...] pois através dele são estabelecidos os critérios que garantem a qualidade e o ajustamento para atender a contento as reais necessidades dos usuários." Concordando com o exposto, Guinchat e Menou (1994, p. 83) enfatizam que esta abordagem é um aspecto primordial e permanente no gerenciamento de uma biblioteca, pois "A seleção dos documentos é uma operação intelectual delicada, que deve ser realizada por um responsável competente no assunto tratado, em colaboração com os usuários.” Essa atividade está integralmente atrelada à finalidade da biblioteca, devendo definir todos os procedimentos 
tomados para selecionar os materiais de informação, constando os critérios e passos com o objetivo de manter a coerência do acervo no transcorrer do tempo, para que todo material adquirido obedeça a razões objetivas e predeterminadas.

O processo de aquisição, por sua vez, implementa as decisões tomadas na seleção. Essa abordagem refere-se em adquirir o material de informação disponível no mercado editorial, por meio de compra, doação e permuta, permitindo a continuidade e atualização da coleção. Segundo Miranda (2007, p. 13), esta abordagem “[...] é o procedimento destinado à obtenção dos documentos." $\mathrm{Na}$ intenção de renovar os espaços para armazenamento e contribuir para melhorar o acesso dos usuários ao material, desencadeia-se o processo de desbastamento, o qual deve ser dinâmico e contínuo (WEITZEL, 2006).

Na concepção de Miranda (2007, p. 16), “Desbastamento é o processo pelo qual se exclui do acervo, títulos e/ou exemplares, partes de coleções, quer para remanejamento, descarte ou conservação (restauração)." O resultado desse processo poderá culminar no descarte ou no remanejamento. O descarte consiste em retirar o material de informação da coleção, ativa ou não, para que seja doado a outras instituições ou definitivamente eliminado do acervo, possibilitando a economia de espaço e otimização do acervo. Miranda (2007) complementa que o material de informação desatualizado é retirado do acervo e não mais incluído na coleção ativa. Durante esse processo, geralmente, são consultados especialistas da área do conhecimento em questão, na intenção de obter parecer favorável.

Por outro lado, o remanejamento consiste em retirar o material de informação do acervo ativo e armazená-lo em locais menos acessíveis, renovando espaços para novos materiais. Geralmente esse material fica organizado à disposição da comunidade, quando solicitado. A avaliação sistemática da coleção determina o valor e a adequação da coleção em relação a seus usuários e em função dos objetivos da instituição. A necessidade de avaliação da coleção é constante e esta abordagem é “[...] um processo contínuo e sistemático, para conservar a qualidade da coleção.” (MIRANDA, 2007, p. 16).

Com o avanço das TIC, é fundamental inferir que as atividades que envolvem o Desenvolvimento de Coleções transformaram-se substancialmente e ao modelo, por ela empregada, foram adicionados elementos resultantes dessa explosão tecnológica, como, por exemplo, os documentos eletrônicos. Esse tema tem sido amplamente discutido na literatura nacional e internacional. O trabalho de Dias, Silva e Cervantes (2012) explora as definições e

\begin{tabular}{l|l|l|l|l|l|l}
\hline (C) Rev. digit. bibliotecon. cienc. inf. & Campinas, SP & v.11 & n.1 & p.39-54 & jan./abr. 2013 & ISSN 1678-765X \\
\hline
\end{tabular}


as peculiaridades que constituem um documento eletrônico, bem como, suas vantagens e aplicações. Este estudo revela ainda como as bibliotecas universitárias nacionais e internacionais estão trabalhando com a política de desenvolvimento de coleções para documentos eletrônicos, identificando um crescimento relevante e a expansão das políticas referentes aos documentos eletrônicos, ainda em fase inicial.

\section{CONSIDERAÇÕES FINAIS}

Em decorrência das presentes reflexões, este trabalho evidenciou a importância do estudo da política de informação científica e tecnológica para o entendimento da atual conjuntura sócio-econômica e cultural da sociedade contemporânea, especificamente no contexto das bibliotecas universitárias. A influência de programas e ações dos institutos e organismos governamentais viabilizaram o desenvolvimento científico e tecnológico nas universidades, implementando políticas de informação explícitas que contemplaram e apoiaram as iniciativas de aceleramento e crescimento do país.

Observa-se que as políticas de informação suscitaram o surgimento de políticas específicas, como por exemplo, para a formação e o desenvolvimento de coleções, a qual possibilita a formação de acervos de acordo com os objetivos da instituição e a disponibilidade de recursos orçamentários, permitindo um processo de seleção sistematizado e consistente das diferentes áreas do acervo.

Nesse panorama, as bibliotecas universitárias são peças fundamentais nesse processo e cabe a elas atender e suprir as demandas informacionais da sua comunidade universitária, cumprindo assim adequadamente suas atividades de ensino, pesquisa e extensão.

\section{REFERÊNCIAS}

ADEKANMB, A. R.; BOADI, B. Y. Problems of developing library collections: a study of colleges of education libraries in Botswana. Inf. Dev., Thousand Oaks, v. 24, n. 4, p. 275-288, nov. 2008. Disponível em:

<http://idv.sagepub.com.ez78.periodicos.capes.gov.br/content/24/4/275.full.pdf+html>.

Acesso em: 10 jan. 2011.

AGUIAR POBLACIÓN, D. et al. Planejamento e gestão de sistemas de informação das bibliotecas universitárias brasileiras: novas tendências ou mudança de paradigmas?. In:

\begin{tabular}{l|l|l|l|l|l|l}
\hline (C) Rev. digit. bibliotecon. cienc. inf. & Campinas, SP & v.11 & n.1 & p.39-54 & jan./abr. 2013 & ISSN 1678-765X \\
\hline
\end{tabular} 
SEMINÁRIO NACIONAL DE BIBLIOTECAS UNIVERSITÁRIAS, 12., 2002, Recife. Anais... Recife: UFPE, 2002. p. 1-13. Disponível em:

<http://www.sibi.ufrj.br/snbu/snbu2002/oralpdf/36.a.pdf $>$. Acesso em: 10 jan. 2011.

AMARAL, A. M. B. M. O cenário da política nacional de informação no Brasil. Inf. Soc., João Pessoa, v. 1, n. 1, p. 47-53, jan./dez. 1991. Disponível em:

<http://www.ies.ufpb.br/ojs2/index.php/ies/article/view/23/1337>. Acesso em: 10 jan. 2011.

AUN, M. P. A construção de políticas nacional e supranacional de informação: desafio para os Estados nacionais e blocos regionais. Cienc. Inf., Brasília, v. 28, n. 2, p. 1-9, maio/ago. 1999. Disponível em: <http://revista.ibict.br/ciinf/index.php/ciinf/article/view/276/244>. Acesso em: 10 jan. 2011.

BARBOSA, M. L. A. A biblioteca e os bibliotecários como atores de políticas de informação voltadas para o desenvolvimento. In: ENCONTRO NACIONAL DE CIÊNCIA DA INFORMAÇAO, 5., 2004, Salvador. Anais... Salvador: UFBA, 2004. Disponível em: <http://www.cinform.ufba.br/v_anais/frames.html>. Acesso em 22 jan. 2011.

BRASIL. Instituto Brasileiro de Informação em Ciência e Tecnologia (IBICT). Histórico. 2005. Disponível em: 〈http://www.ibict.br/ secao.php?cat=Biblioteca\%20do\%20Ibict/ Hist\%F3rico $>$. Acesso em: 10 jan. 2011.

BRASIL. Ministério da Educação e Cultura. Campanha Nacional de Aperfeiçoamento de Pessoal de Nível Superior (CAPES). História e missão. 2011. Disponível em:

<http://www.capes.gov.br/sobre-a-capes/historia-e-missao/>. Acesso em: 10 jan. 2011.

CARIDAD SEBASTIÁN, M.; MÉNDEZ RODRIGUEZ, E. M.; RODRIGUEZ MATEOS, D. La necessidad de políticas de información ante la nueva sociedad globalizada: el caso español. Cienc. Inf., Brasília, v. 29, n. 2, p. 22-36, maio/ago. 2000. Disponível em: <http://revista.ibict.br/ciinf/index.php/ciinf/article/view/249/217>. Acesso em: 10 jan. 2011. CARVALHO, I. C. L. A socialização do conhecimento no espaço das bibliotecas universitárias. Niterói: Intertexto, 2004.

CAVALCANTE, L. E. Políticas de formação para a competência informacional: o papel das universidades. Rev. Bras. Bibl. Doc., São Paulo, v. 2, n. 2, p. 47-62, dez. 2006. Disponível em: 〈http://www.febab.org.br/rbbd/ojs-2.1.1/index.php/rbbd/article/view/17/5 >. Acesso em: 10 jan. 2011.

CNPq: 50 anos de ciência. Pesquisa FAPESP, São Paulo, n. 64, p. 1-6, maio. 2001. Disponível em: <http://revistapesquisa.fapesp.br/?art=1304\&bd=1\&pg=1\&lg=>. Acesso em: 10 jan. 2011.

COORDENAÇÃO DE APERFEIÇOAMENTO DE PESSOAL DE NÍVEL SUPERIOR CAPES. Histórico. Disponível em: <http://www.capes.gov.br/sobre-a-capes/historia-emissao>. Acesso em: 16 nov. 2011a. 
CONSELHO NACIONAL DE DESENVOLVIMENTO CIENTÍFICO E TECNOLÓGICO CNPQ. História do CNPQ. Disponível em: 〈http://centrodememoria.cnpq.br/Missao.html〉. Acesso em: 10 jan. 2011.

CORREA, E. C. D. Os usos do computador e a definição do campo da Ciência da Informação em relação à Biblioteconomia no Brasil: uma análise sociotécnica. 2008. 245 f. Tese (Doutorado em Sociologia Política) - Universidade Federal de Santa Catarina, Florianópolis. 2008. Disponível em: <http://www.pergamum.udesc.br/dados-bu/000000/00000000000B/00000B5F.pdf $>$. Acesso em: 27 fev. 2012.

COSTA, A. R. F. Política nacional de informação científica e tecnológica: necessidade versus realidade. Inf. Soc., João Pessoa, v. 1, n. 1, p. 44-55, 1991. Disponível em:

<http://www.ies.ufpb.br/ojs2/index.php/ies/article/view/21/1335>. Acesso em: 10 jan. 2011.

CUNHA, M. B. IBICT: 51 anos. Brasília, Cienc. Inf., Brasília, v. 34, n. 1, p.7-8, jan./abr. 2005. Disponível em: 〈http://revista.ibict.br/ciinf/index.php/ciinf/article/view/694/589>. Acesso em: 10 jan. 2011.

DIAS, G. D.; SILVA, T. E.; CERVANTES, B. M. N. Política de desenvolvimento de coleções para documentos eletrônicos: tendências nacionais e internacionais. Enc. Bibli: R. Eletr. Bib. Ci. Inf., Florianópolis, v. 17, n. 34, p.42-56, maio/ago., 2012. Disponível em: <http://www.periodicos.ufsc.br/index.php/eb/article/view/1518-2924.2012v17n34p42/22652>. Acesso em: 20 Nov. 2012.

DUTRA, A. K. F.; OHIRA, M. L. B. Informatização e automação de bibliotecas: análise das comunicações apresentadas nos seminários nacionais de bibliotecas universitárias $(2000,2002$ e 2004). Inf. Inf., Londrina, v. 9, n. 1/2, jan./dez. 2004. Disponível em:〈http://www.uel.br/revistas/uel/index.php/informacao/article/viewFile/1725/1476>. Acesso em 10 jan. 2011.

GOMES, M.Y. F. S. F. O Estado e o processo de implantação de uma política nacional de informação científica e tecnológica no Brasil. Cienc. Inf., Brasília, v. 17, n. 2, p. 105-117, jul./dez. 1988.

GONZÁLEZ DE GÓMEZ, M. N. Novos cenários políticos para a informação.

Cienc. Inf., Brasília, v. 31, n. 1, p. 27-40, jan./abr. 2002. Disponível em: <http://revista.ibict.br/ciinf/index.php/ciinf/article/view/170/149>. Acesso em: 10 jan. 2011.

GUINCHAT, C.; MENOU, M. Introdução geral às ciências e técnicas da informação e documentação. 2. ed. Brasília: MCT/CNPq/IBICT/ Fundação Banco do Brasil, 1994.

KLAES, R. R. Dados e informações usados na tomada de decisão em bibliotecas universitárias brasileiras: o contexto da atividade de desenvolvimento de coleções. 1991. 271 f. Dissertação (Mestrado em Biblioteconomia e Documentação) - Universidade de Brasília, Brasília, 1991.

\begin{tabular}{l|l|l|l|l|l|l} 
(C) Rev. digit. bibliotecon. cienc. inf. & Campinas, SP & v.11 & n.1 & p.39-54 & jan./abr. 2013 & ISSN 1678-765X \\
\hline
\end{tabular}


MACHADO, R. N.; SILVA, Z. P. Desenvolvimento de coleções: uma análise a partir dos anais dos SNBUs realizados na década de 90. In: SEMINÁRIO NACIONAL DE BIBLIOTECAS UNIVERSITÁRIAS, 12., 2002, Recife. Anais... Recife: UFPE, 2002. Disponível em: <http://www.sibi.ufrj.br/snbu/snbu2002/oralpdf/121.a.pdf >. Acesso em: 10. jan. 2011.

MIRANDA, A. C. C. Desenvolvimento de coleções em bibliotecas universitárias. Rev. Digit. Bibl. Cienc. Inf., Campinas, v. 4, n. 2, p. 1-19, jan./jun. 2007. Disponível em:

<http://www.sbu.unicamp.br/seer/ojs/viewarticle.php?id=103\&layout=abstract $>$. Acesso em: 10 jan. 2011.

NORONHA, D. P. et al. A contribuição da pesquisa dos docentes dos programas de pósgraduação em ciência da informação nos SNBUs (2000-2004). In: SEMINÁRIO NACIONAL DE BIBLIOTECAS UNIVERSITÁRIAS, 14., 2006, Salvador. Anais... Salvador: UFBA, 2006. Disponível em: 〈http://www.eca.usp.br/nucleos/pc/artigo/DaisySNBU2006.pdf>. Acesso em: 10 jan. 2011.

NUNES, S. M.; SANTOS, L. S. Políticas de informação e aprendizagem organizacional: desafios para a implantação de novas tecnologias em bibliotecas universitárias. Comun. Inf., Goiânia, v. 10, n. 1, p. 73 - 81, jan/jun. 2007. Disponível em:

<http://www.revistas.ufg.br/index.php/ci/article/view/10311/7160 > . Acesso em: 10 jan. 2011.

ORNA, E. Information policies: yesterday, today, tomorrow. J. Inf. Sci., Cambridge, v. 34, n. 4, p. 547-565, ago. 2008. Disponível em: $<$ http://jis.sagepub.com.ez78.periodicos. capes.gov.br/content/34/4/547.full.pdf+html>. Acesso em: 10 jan. 2011.

SILVA, E. M. A influência das políticas de informação científica e tecnológica para as bibliotecas universitárias. 2009. 103 f. Dissertação (Mestrado em Ciência da Informação) Universidade Federal da Paraíba, João Pessoa, 2009. Disponível em: $<$ http://dci2.ccsa.ufpb.br:8080/jspui/bitstream/123456789/120/1/Disserta\%C3\%A7\%C3\%A3 o\%20CI\%20EDILENE\%20M\%20SILVA.pdf>. Acesso em: 18 jan. 2011.

SILVA, E. M.; GARCIA, J. C. R. Política de informação científica e tecnológica no Brasil: contribuição para as bibliotecas universitárias. In: ENCONTRO NACIONAL DE PESQUISA EM CIENCIA DA INFORMACAO, 10., 2009, João Pessoa. Anais... João Pessoa: ANCIB; UFPG; PPGCI, 2009. Disponível em: <http://dci2.ccsa.ufpb.br:8080/jspui/bitstream/ 123456789/447/1/GT\%205\%20Txt\%2014-20GARCIA\%2cJoana\%20C.\%20R.\%3b\%20SILVA \%2c\%20Edilene\%20M.\%20da.\%20Pol\%C3\%ADtica\%20de...pdf>. Acesso em: 15 jan. 2011.

SILVA, L. A. G. Visão panorâmica do planejamento de sistemas de bibliotecas universitárias. In: SEMINÁRIO NACIONAL DE BIBLIOTECAS UNIVERSITÁRIAS, 2., 1981, Brasília. Anais... Brasília: CAPES, 1981. p. 53-60. 
SILVA, T. E. Política de informação na pós-modernidade: reflexões sobre o caso do Brasil. Inf. Soc., João Pessoa, v. 1, n. 1, p. 8-13, jan./dez. 1991. Disponível em: <http://www.ies.ufpb.br/ojs2/index.php/ies/article/view/18/1332>. Acesso em: 15 jan. 2011.

TARAPANOFF, K. Planejamento de e para bibliotecas universitárias no Brasil: sua posição sócio-econômica e estrutural. In: SEMINÁRIO NACIONAL DE BIBLIOTECAS UNIVERSITÁRIAS, 2., 1981, Brasília. Anais... Brasília: CAPES, 1981. p. 9-35.

VERGER, J. Homens e saber na Idade Média. Bauru: EDUSC, 1999.

VERGUEIRO, W. Desenvolvimento de coleções. São Paulo: Polis; APB, 1989.

Desenvolvimento de coleções: uma nova visão para o planejamento de recursos informacionais. Cienc. Inf., Brasília, DF, Brasil, 22, abr. 1993. Disponível em:

<http://revista.ibict.br/ciinf/index.php/ciinf/article/view/1208/849>. Acesso em: 20 Nov. 2012.

WEITZEL, S. R. O desenvolvimento de coleções e a organização do conhecimento: suas origens e desafios. Perspect. Cienc. Inf., Belo Horizonte, v. 7, n. 1, p. 61-67, jan./jun. 2002. Disponível em: 〈http://portaldeperiodicos.eci.ufmg.br/index.php/pci/article/viewFile/414/227>. Acesso em: 20 jan. 2011.

Elaboração de uma política de desenvolvimento de coleções em bibliotecas universitárias. Rio de Janeiro: Interciência, 2006.

WILLIAMS, V. K.; FLETCHER, C. L. Materials used by master's students in engineering and implications for collection development: a citation analysis. Science and Technology Librarianship, Chicago, n. 45, winter, 2006. Disponível em:

<http://www.library.ucsb.edu/istl/06-winter/refereed1.html >. Acesso em: 20 jan. 2011.

\section{Como citar este artigo:}

DIAS, Geneviane Duarte; SILVA, Terezinha Elizabeth da; CERVANTES, Brígida Maria Nogueira. Políticas de informação nas bibliotecas universitárias: um enfoque no desenvolvimento de coleções. Rev. digit. bibliotecon. cienc. inf., Campinas, SP, v.11, n.1, p.39-59, jan./abr. 2012. ISSN 1678-765X. Disponível em: $<$ http://www.sbu.unicamp.br/seer/ojs/índex.php>.

\begin{tabular}{l|l|l|l|l|l|l}
\hline (C) Rev. digit. bibliotecon. cienc. inf. & Campinas, SP & v.11 & n.1 & p.39-54 & jan./abr. 2013 & ISSN 1678-765X \\
\hline
\end{tabular}

